\title{
Anti-flagellin antibody responses elicited in mice orally immunized with attenuated Salmonella enterica serovar Typhimurium vaccine strains
}

\author{
LM Massis/ ${ }^{+}$, CJM Braga, ME Sbrogio-Almeida', C Lauand, SMC Newton², PE Klebba², \\ LCS Ferreira
}

\begin{abstract}
Departamento de Microbiologia, Instituto de Ciências Biomédicas, Universidade de São Paulo, Av. Prof. Lineu Prestes 1374, 05508-000 São Paulo, SP, Brasil 'Divisão de Desenvolvimento Tecnológico e Produção, Instituto Butantan, São Paulo, SP, Brasil ²Department of Chemistry and Biochemistry, University of Oklahoma, Norman, OK, USA
\end{abstract}

In the present study we investigated the flagellin-specific serum (IgG) and fecal (IgA) antibody responses elicited in BALB/c mice immunized with isogenic mutant derivatives of the attenuated Salmonella enterica serovar Typhimurium (S. Typhimurium) SL3261 strain expressing phase 1 (FliCi), phase 2 (FljB), or no endogenous flagellin. The data reported here indicate that mice orally immunized with recombinant $\mathrm{S}$. Typhimurium strains do not mount significant systemic or secreted antibody responses to FliCi, FljB or heterologous B-cell epitopes genetically fused to FliCi. These findings are particularly relevant for those interested in the use of flagellins as molecular carriers of heterologous antigens vectored by attenuated $\mathrm{S}$. Typhimurium strains.

Key words: fagellin - antibody response - attenuated $S$. Typhimurium strains

Attenuated Salmonella enterica strains have been studied intensively as live carriers of heterologous vaccine antigens delivered by mucosal or parenteral routes (Brey et al. 1991, Garmory et al. 2002). Orally delivered, attenuated Salmonella strains induce both systemic and secretory immune responses against the carrier strain as well as the heterologous passenger antigen (Garmory et al. 2002). Additionally, peptides, particularly those encoding B-cell epitopes, may be expressed by attenuated Salmonella strains as hybrid proteins following genetic fusion to bacterial proteins. This approach may improve both the stability and the immunogenicity of target antigens delivered orally in live bivalent vaccines (Dougan et al. 1987, Chatfield et al. 1992).

The fusion of heterologous antigens to Salmonella flagellin, the structural subunit of bacterial flagella, has piqued considerable interest as an approach to enhancing the immunogenicity of vaccine peptides (Newton et al. 1989, Stocker 1990, Newton et al. 1991, Stocker \& Newton 1994). As originally proposed, the heterologous peptide is fused in-frame to the central hypervariable domain of Salmonella FliCd flagellin, which is derived from Salmonella Müenchen and expressed by an attenuated Salmonella Dublin strain. The chimeric flagellins are exported to the bacterial surface where the subunits assemble into the flagellar shaft without a significant impact on bacterial motility and host tissue colonization (Newton et al. 1989, Stocker \& Newton 1994). Nonethe-

Financial support: CNPq, FAPESP, NIH grant GM53836, NSF grant MCB0417694, FAPESP, CAPES

+ Corresponding author: 1mmassis@usp.br

Received 15 April 2008

Accepted 22 August 2008 less, our previous results showed that the genetic fusion of heterologous peptides to flagellins may not enhance antigen-specific antibody responses in mice orally immunized (p.o.) with recombinant $S$. Dublin vaccine strains (De Almeida et al. 1999, Sbrogio-Almeida \& Ferreira 2001). Interestingly, the genetic background of both the mouse lineage and the Salmonella strain affected the immunogenicity of flagellins delivered orally using recombinant vaccine strains (Sbrogio-Almeida 2004). Indeed, recent evidence indicates that Salmonella flagellin administered via the oral route may trigger immunological hyporesponsive responses in healthy mice, although the precise mechanism underlying these responses remains unknown (Sanders et al. 2006).

In contrast to $S$. Dublin strains, wild-type $S$. Typhimurium strains express two flagellar phases: phase 1 (FliCi) and phase 2 (FljB), which are alternately produced by a single cell but may be found concurrently in the same bacterial population (Ikeda et al. 2001, Yamamoto \& Kutsukake 2006). So far, the oral immunogenicity of the two $S$. Typhimurium flagellins, as well as their role as potential heterologous peptide carriers, has not been investigated. To explore these issues, the present study analyzed the antibody-inducing properties of flagellins expressed by the attenuated $S$. Typhimurium SL3261 strain.

The bacterial strains and plasmids used in this study are described in Table I. Recombinant plasmids were introduced by electroporation into the non-flagellated $S$. Typhimurium strain LDV321. The plasmid pFF400 is a pUC18 derivative carrying the $f l i C$ gene of SL3261. pFF408 was constructed by replacing a 48 bp region between two natural $E c o R V$ sites with a polylinker containing unique $\mathrm{XhoI}$ and $\mathrm{BglII}$ sites at the central region of FliCi-encoding gene (Newton et al. 1989). pFF302 is a pFF408 derivative that carries a hybrid fliCi gene encoding a 15-amino acid peptide (VDPVIDLLQADGNAL). This peptide defines $\mathrm{B}$ and T-cell epitopes of the structural subunit $(\mathrm{CfaB})$ of the $\mathrm{CFA} / \mathrm{I}$ fimbriae from entero- 
TABLE I

Salmonella Typhimurium strains and plasmids used in the present study

\begin{tabular}{|c|c|c|}
\hline Strains & Relevant characteristics & Reference \\
\hline SL3261 & $\operatorname{aro} A$, his & Hoiseth \& Stocker 1981 \\
\hline LDV321 & aro $A$, his; fliC(i)::FRT ${ }^{a}$, fljBA::FRT & This study \\
\hline LDV322 & aro $A$, his; fljBA::FRT & This study \\
\hline LDV323 & aro $A$, his; fliC(i)::FRT & This study \\
\hline LDV3211 LDV321,pFF408 & & This study \\
\hline LDV325 LDV321,pFF411 & & This study \\
\hline LDV3212 LDV321, pFF302 & & This study \\
\hline TT22971 & $\begin{array}{l}\text { metA22 metE551 trpD2 ilv-452 leu pro } \\
\text { hsdLT6 hsdSA29 hsdB strA120 }\end{array}$ & Court et al. 2002 \\
\hline \multicolumn{3}{|c|}{ (1) } \\
\hline pKD46 & $\begin{array}{l}\text { araC, bla, oriR101, repA101(Ts), } \\
\text { lambda red genes }\left(\text { gam }^{+} \text {bet }^{+} \text {exo }\right)\end{array}$ & Datsenko \& Wanner 2000 \\
\hline pCP20 & $F L P^{+}, \lambda \operatorname{cI} 857+, \lambda \mathrm{p}_{\mathrm{R}} \operatorname{Rep}^{\mathrm{ts}}$, bla, cat $F$ & Cherepanov \& Wackernagel 1995 \\
\hline pFF408 & $\begin{array}{l}\text { pUC18 derivative containing the fliCi gene } \\
\text { with a deletion of } 48 \mathrm{bp} \text {, bla }\end{array}$ & This study \\
\hline pFF411 & $\begin{array}{l}\text { pFF } 408 \text { derivative with a } 45 \text { bp insert } \\
\text { encoding the CTP } 3 \text { epitope }\end{array}$ & This study \\
\hline pFF302 & $\begin{array}{l}\text { pFF408 derivative with a } 45 \text { bp insert } \\
\text { encoding the } \mathrm{CfaB}_{11-25} \text { epitope }\end{array}$ & This study \\
\hline
\end{tabular}

$a$ : FRT- FLP Recognition Target (Cherepanov \& Wackernagel 1995).

toxigenic Escherichia coli (ETEC) (Luna et al. 1997) at the FliCi central hypervariable domain. Similarly, pFF411 delivers a recombinant fliCi gene encoding the 15 amino acid-long CTP3 peptide (VEVPGSQHIDSQKKA) derived from the B subunit of the cholera toxin (Newton et al. 1989) at the same flagellin domain.

Flagellin-deficient $S$. Typhimurium strains have been generated following chromosomal deletions of each native flagellin gene ( $f l i C i$ and $f l j B$ ) by allelic replacement (Datsenko \& Wanner 2000). Primers were designed based on the flagellin sequences of the $S$. Typhimurium LT2 strain (McClelland et al. 2001). Deletion of $f l j B$ also included the $f l j A$ gene, which encodes the $f l i C$ gene transcriptional repressor. The amplified fragments were introduced by electroporation into the attenuated SL3261 strain transformed with the arabinose-inducible red genes-encoding plasmid (pKD46), previously propagated in the restriction minus $\left(\mathrm{rm}^{+}\right)$ metilation plus $S$. Typhimurium TT22971 strain. The phage lambda recombinase allows high-frequency recombination between linear DNA fragments generated by polymerase chain reaction (PCR) and homologous regions in the bacterial chromosome (Datsenko \& Wanner 2000). To avoid undesirable mutations and to obtain the double-deletion mutant $(\triangle f l i C, \triangle f l j B A)$ the strains were submitted to transductional crosses using a high frequency-transducing P22 phage (HT105 int) as previously described (Schmieger 1971). The strains were also transformed with pCP20, encoding resistance to ampicillin and chloramphenicol, to remove the resistance cassettes inserted in the target chromosomal sites. As previously reported, this plasmid undergoes temperature-sensitive replication and induction of $f l p$ (the gene encoding the Saccharomyces cerevisiae Flp recombi- nase) synthesis after a temperature shift (Cherepanov \& Wackernagel 1995). The genomic deletions of the resulting $S$. Typhimurium LDV322 ( $\triangle f l j B A)$, LDV323 $(\Delta f l i C)$ and LDV321 $(\triangle f l i C, \triangle f l j B A)$ strains were confirmed by PCR and immunoblot assays. Sodium dodecyl sulfate polyacrylamide gel electrophoresis was performed according to standard procedures (Sbrogio-Almeida \& Ferreira 2001). Motility was assessed by applying the bacterial strains to the center of plates containing $0.35 \%$ agar, followed by incubation at $37^{\circ} \mathrm{C}$ for $32 \mathrm{~h}$. Motility agar plates were prepared according to previously established methods (Ikeda et al. 2001).

Flagellins expressed by $S$. Typhimurium LDV322 or LDV323 were harvested from cultures incubated overnight under mild aeration $(80 \mathrm{rpm})$ at $37^{\circ} \mathrm{C}$. Cells were collected by centrifugation, suspended in phosphatebuffered saline ( $\mathrm{pH}$ 7.4) and homogenized for $2 \mathrm{~min}$ using a bench mixer. The cells were maintained on ice and the above procedure was repeated three times. The mixture was then centrifuged at $10,000 \mathrm{~g}$ for $10 \mathrm{~min}$ to remove the bacteria and flagella were collected from the supernatant following acetone precipitation. Contaminating lipopolysaccharide (LPS) was removed using a gel-detoxi column (Pierce). Recombinant His-tagged FliCi flagellin was produced in E. coli transformed with pET28a carrying the cloned fliCi gene. Protein concentration was measured using the BCA quantification method (Pierce).

Isogenic, pathogen-free 8-12 week old female BALB/c mice were supplied by the Isogenic Mouse Breeding Facility of the Departamento de Parasitologia do Instituto de Ciências Biomédicas da Universidade de São Paulo and all procedures were approved by the ethics committee on use of laboratory animals. Immunizations were 
carried out using viable bacterial strains harvested during exponential growth (optical density at $600 \mathrm{~nm}$ of 0.8 ). Mice were p.o. with $0.5 \mathrm{ml}$ aliquots of approximately $10^{10}$ CFU using a stainless steel, round-tip gavage cannule on days 0,21 and 35 . The same immunization schedule was followed for the intraperitoneally (i.p.) immunizations, but the bacterial loads were reduced to $10^{7} \mathrm{CFU}$ per dose. Serum and fecal wash samples were collected individually, but samples belonging to the same immunization groups (with 5-10 individuals) were pooled for antibody titer determination (Sbrogio-Almeida \& Ferreira 2001).

Microtiter plates (Nalge Nunc) were coated $(0.1 \mu \mathrm{g} /$ well) with purified FliCi and $\mathrm{FljB}$ or the $\mathrm{CfaB}$ (Luna et al. 1997) and CTP3 oligopeptides (De Almeida et al. 1999) in $0.05 \mathrm{M}$ sodium bicarbonate buffer ( $\mathrm{pH}$ 9.6) overnight at RT. Experimental procedures for detecting specific serum IgG and fecal IgA responses have been described previously (Sbrogio-Almeida et al. 2004).

Isogenic flagellin-deficient knockout mutants of the attenuated $S$. Typhimurium SL3261 strain, affected in either $f l i C i$, $f l j B$ or both genes, were selected after homologous recombination mediated by the bacteriophage lambda recombinase encoded by the red genes (Fig. 1). In vitro tests carried out with the flagellin-deficient derivatives of the $S$. Typhimurium SL3261 strain showed that deletion of either fliCi or $f l j B$ did not impair the motility of the respective strains. Nonetheless, as expected, deletion of both flagellin-encoding genes rendered the LDV321 strain non-motile (Fig. 1).

Initial attempts to measure the flagellin-specific antibody responses in vaccinated mice indicated that mice immunized with the $S$. Typhimurium SL3261 or

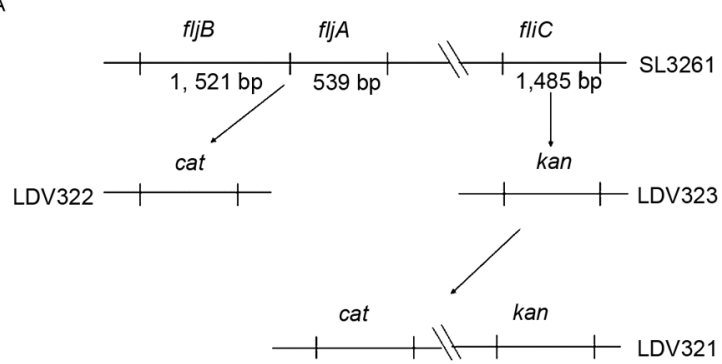

C
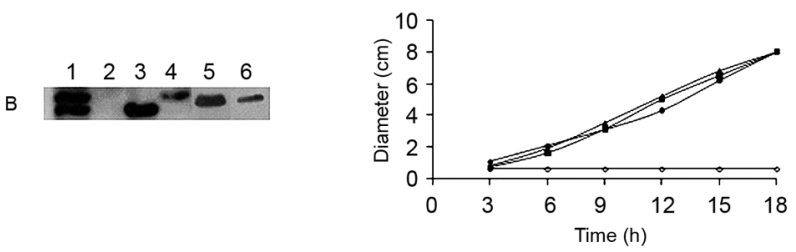

Fig. 1: generation of flagellin-deficient Salmonella Typhimurium strains. A: schematic representation of the construction steps leading to $S$. Typhimurium strains expressing only FliCi (LDV322), FljB (LDV323) or none flagellin (LDV321); B: immunological detection of flagellins expressed by different $S$. Typhimurium strains. Lanes 1: SL3261 strain; 2: LDV321 strain; 3: LDV322 strain; 4: LDV323 strain; 5: LDV325 strain; 6: LDV3212 strain; C: in vitro motility of $S$. Typhimurium strains on a semi-solid medium at $37^{\circ} \mathrm{C}$; tested strains: SL3261 (•); LDV321 (O); LDV322 (ム); LDV323 (•).
LDV321 strains mounted similar systemic and secreted anti-flagellin antibody responses following oral administration (Fig. 2). As demonstrated in Fig. 3, removal of LPS from flagellin preparations drastically reduced the reactivity of sera in mice immunized with the Salmonella strains. Indeed, the recombinant FliCi flagellin, produced in E. coli, reacted weakly with the antibodies generated in mice p.o. with the SL3261 strain (Fig. 3). Additionally, western blots carried out with Salmonella flagellin preparations and sera from mice vaccinated with the $S$. Typhimurium SL3261 strain showed that, besides the contaminant LPS present in flagellin preparations, a minor protein with an estimated molecular mass of $35 \mathrm{kDa}$ and not detected in Coomassie blue-stained gels reacted with the tested serum sample (Fig. 3).

A

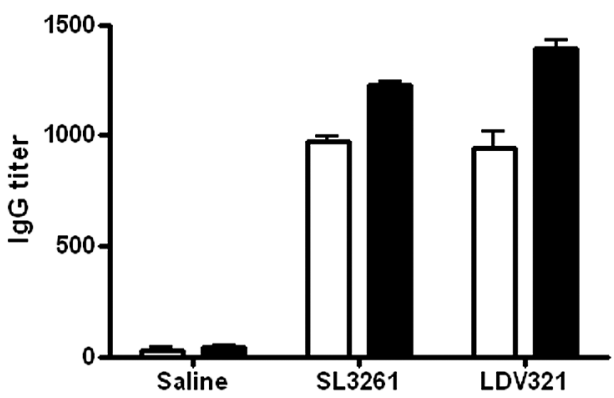

B

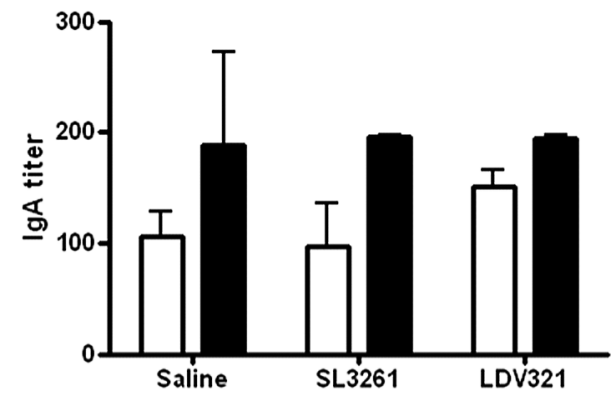

C

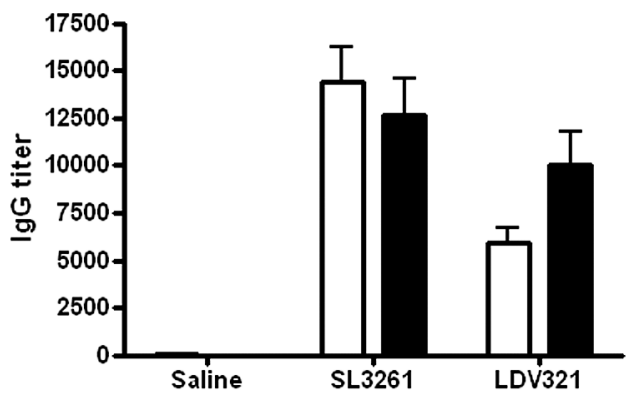

Fig 2: specific antibody responses to flagellins in BALB/c mice immunized with Salmonella Typhimurium SL3261 or LDV321 strains. A: serum IgG responses to FliCi (white bars) and FljB (black bars) after oral immunization with the $S$. Typhimurium strains expressing FliCi and FljB (SL3261) or none (LDV321) flagellin; B: fecal IgA responses to flagellins after p.o. with the $S$. Typhimurium SL3261 or LDV321 strains; C: serum IgG responses to flagellins after immunization with the $S$. Typhimurium strains via intraperitoneally immunization route; control groups represented by non immunized mice; values are means of endpoint titers \pm SEM of serum pools $(\mathrm{n}=5)$ prepared from each mouse group. 
The following Enzyme Linked Immuno Sorbent Assay (ELISA) measurements were thus carried out using LPS-free Salmonella flagellin preparations. The results obtained after the p.o. trials with the $S$. Typhimurium SL3261, LDV322 or LDV323 strains indicated that no significant flagellin-specific serum IgG responses were induced in mice immunized with the flagellated $S$. Typhimurium strains (Table II). Similar conclusions were drawn following measurement of flagellin-specific IgA in fecal extracts of mice p.o. with flagellated $S$. Typhimurium vaccine strains (data not shown). In contrast, mice immunized via the i.p. route with flagellated $S$. Typhimurium strains developed high $\mathrm{FliC} i$ or FljB-specific serum IgG responses following vaccination with the LDV322 or LDV323 strain, respectively (Table II). Collectively, these results indicate that mice p.o. with flagellated $S$. Typhi-

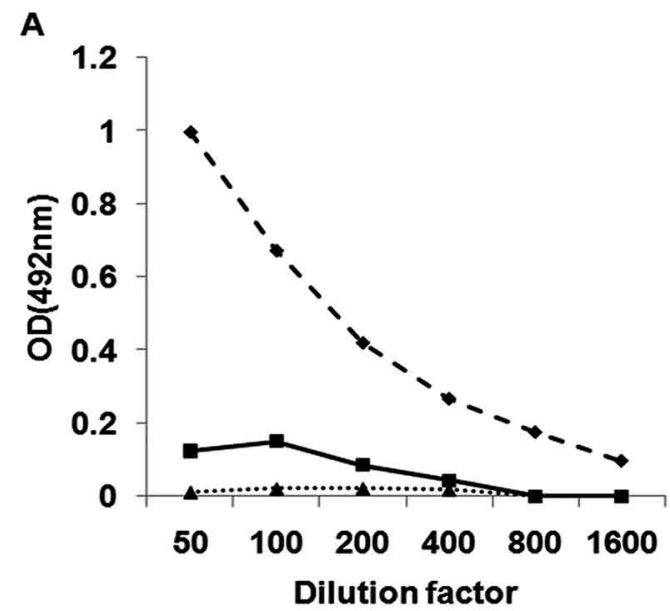

B

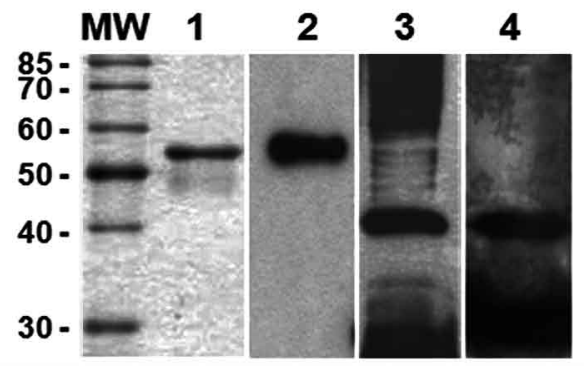

Fig. 3: detection of non-specific reaction of serum samples harvested from mice immunized with the Salmonella Typhimurium SL3261 strain. A: ELISA carried out with different solid phase bound antigen preparations: crude FliCi preparation extracted from $S$. Typhimurium $(\downarrow)$; lipopolysaccharide (LPS) free FliCi preparation (๘) and affinity purified $S$. FliCi produced by a recombinant Escherichia coli strain $(\mathbf{\Lambda})$; B: detection of cross-reacting materials in flagellin preparations extracted from $S$. Typhimurium SL3261. Lanes MW: molecular weight markers; 1: Coomassie blue-stained FliCi preparation $(1 \mu \mathrm{g})$; 2: immunoblot developed with anti-FliCi serum raised in mice immunized with purified protein; 3 : immunoblot developed with serum pool $(\mathrm{n}=5)$ harvested from mice orally immunized with the $S$. Typhimurium SL3261 strain; 4: immunoblot of a LPS-free FliCi preparation developed with serum pool $(n=5)$ harvested from mice orally immunized with the $S$. Typhimurium SL3261 strain. murium strains did not develop significant systemic or secreted flagellin-specific antibody responses.

To determine if the lack of antibody responses to $S$. Typhimurium flagellins observed in mice p.o. immunized with the attenuated LDV3212 or LDV325 strain would affect antibody responses to heterologous epitopes genetically fused at the central hypervariable region of $\mathrm{FliCi}$, we measured the systemic (serum $\mathrm{IgG}$ ) and secreted (fecal $\operatorname{IgA}$ ) responses to peptides derived from the ETEC CFA/I fimbriae structural subunit and the B subunit of cholera toxin. Although the presence of the flagellin inserts could be confirmed by either DNA sequencing or western blot with anti-flagellin serum (Fig. 1B and unpublished observations), BALB/c mice p.o. with the recombinant $S$. Typhimurium strains did not develop significant serum or fecal antibody responses to the he-terologous epitopes (data not shown).

Using the isogenic, flagellin-deficient $S$. Typhimurium strains, it was possible to show that the previously detected flagellin-specific serum antibody responses elicited in mice p.o. with flagellated strains were due to the presence of contaminating LPS, as well as an outer membrane protein in flagellin preparations used as solid-phase bound antigen. Thus, the generation of flagellin preparations with higher purity and the use of a nonflagellated strain helped us to demonstrate that mice p.o. with flagellated $S$. Typhimurium strains failed to mount significant systemic and secreted flagellin-specific antibody responses, similar to results previously reported for $S$. Dublin strains (Sbrogio \& Almeida 2001, Sbrogio et al. 2004, Sanders et al. 2006).

Since mice parenterally immunized with flagellated $S$. Typhimurium strains developed strong antibody re-

\section{TABLE II}

Flagellin-specific antibody responses (serum IgG and fecal IgA) elicited in BALB/c mice immunized via the oral (p.o.) or intraperitoneally (i.p.) immunization routes with the Salmonella Typhimurium SL3261 strain and its flagellindeficient derivatives

\begin{tabular}{lccc}
\hline Strains & $\begin{array}{c}\text { Immunization } \\
\text { routes }^{a}\end{array}$ & \multicolumn{2}{c}{ Flagellin antibody responses } \\
& & \multicolumn{2}{c}{ Serum IgG $^{b}$} \\
\cline { 3 - 4 } S. Typhimurium & & AntiFliCi & AntiFljB $^{*}$ \\
\hline SL3261 & oral & $36 \pm 0.10$ & 0 \\
& i.p. & $11,626 \pm 0.19$ & $5,986 \pm 0.25$ \\
LDV322 & oral & 0 & ND \\
& i.p. & $5,331 \pm 0.2$ & ND \\
LDV323 & oral & ND & 0 \\
& i.p. & ND & $10,690 \pm 0.25$ \\
\hline
\end{tabular}

$a$ : immunizations were carried out with three doses of $10^{10}$ CFU p.o. or $10^{7}$ CFU i.p. on days 0, 21 and 35. Serum and fecal samples were collected one week after the last immunization dose; $b$ : titers were determined in ELISA plates treated with purified FliCi or FljB flagellins. Data are based on two independent experiments; $c$ : values are means of endpoint titers \pm SEM of serum pools $(n=5)$ prepared from each mouse group; ND: not done. 
sponses to flagellins, the observed flagellin-hyporesponsive state might be restricted to the murine mucosal immune system. Recent findings confirmed that bacterial flagellins do not elicit inflammatory responses in the normal gut epithelium, a behavior explained by the lack of functional TLR5 expression at the apical surface of enterocytes (Gewirtz et al. 2001), the activation of apoptotic responses by flagellin-exposed antigenpresenting cells (Ren et al. 2006) and/or the activation of suppressive $\mathrm{CD} 4^{+} \mathrm{CD} 25^{+} \mathrm{T}$ regulatory cells (Crellin et al. 2005). Although our findings indicate that the expression of chimeric flagellins by recombinant attenuated $S$. Typhimurium strains has an inherently reduced immunogenicity as an oral bivalent vaccine approach, stimulation of specific immune responses triggered by purified flagellins delivered via the nasal or parenteral routes (Honko et al. 2006) represents more promising alternative for the use of Salmonella flagellins in vaccine development.

\section{ACKNOWLEDGMENTS}

To Dr. Melissa A S Lasaro (University of Pennsylvania) and Dr. Karina R Bortoluci (Universidade de São Paulo), for helpful comments, and Camila F P Calderon, Carlos A da Silva and Aline F Teixeira, for invaluable technical assistance.

\section{REFERENCES}

Brey RN, Bixler GS, Fulginiti JP, Dilts DA, Sabara MI 1991. Oral delivery of antigens in live bacterial vectors. Adv Exp Med Biol 303: 169-184.

Chatfield SN, Charles IG, Makoff AJ, Oxer MD, Dougan G, Pickard D, Slater D, Fairweather NF 1992. Use of the nirB promoter to direct the stable expression of heterologous antigens in Salmonella oral vaccine strains: development of a single-dose oral tetanus vaccine. Biotechnology (NY) 10: 888-892.

Cherepanov PP, Wackernagel W 1995. Gene disruption in Escherichia coli: TcR and KmR cassettes with the option of Flp-catalyzed excision of the antibiotic-resistance determinant. Gene 158: 9-14.

Court DL, Sawitzke JA, Thomason LC 2002. Genetic engineering using homologous recombination. Annu Rev Genet 36: 361-388.

Crellin NK, Garcia RV, Hadisfar O, Allan SE, Steiner TS, Levings MK 2005. Human $\mathrm{CD}^{+} \mathrm{T}$ cells express TLR5 and its ligand flagellin enhances the suppressive capacity and expression of FOXP3 in $\mathrm{CD} 4{ }^{+} \mathrm{CD} 25^{+} \mathrm{T}$ regulatory cells. J Immunol 175 : 8051-8059.

Datsenko KA, Wanner BL 2000. One-step inactivation of chromosomal genes in Escherichia coli K-12 using PCR products. Proc Natl Acad Sci USA 97: 6640-6645.

De Almeida ME, Newton SM, Ferreira LC 1999. Antibody responses against flagellin in mice orally immunized with attenuated Salmonella vaccine strains. Arch Microbiol 172: 102-108.

Dougan G, Hormaeche CE, Maskell DJ 1987. Live oral Salmonella vaccines: potential use of attenuated strains as carriers of heterologous antigens to the immune system. Parasite Immunol 9: 151-160.

Garmory HS, Brown KA, Titball RW 2002. Salmonella vaccines for use in humans: present and future perspectives. FEMS Microbiol Rev 26: 339-353.
Gewirtz AT, Simon PO Jr., Schmitt CK, Taylor LJ, Hagedorn CH, O'Brien AD, Neish AS, Madara JL 2001. Salmonella typhi-murium translocates flagellin across intestinal epithelia, inducing a proinflammatory response. J Clin Invest 107: 99-109.

Hoiseth SK, Stocker BA 1981. Aromatic-dependent Salmonella Typhimurium are non-virulent and effective as live vaccines. Nature 291: 238-239.

Honko A, Sriranganathan N, Lees CJ, Mizel SB 2006. Flagellin is an effective adjuvant for immunization against lethal respiratory challenge with Yersinia pestis. Infect Immun 74: 1113-1120.

Ikeda JS, Schmitt CK, Darnell SC, Watson PR, Bispham J, Wallis TS, Weinstein DL, Metcalf ES, Adams P, O'Connor CD, O'Brien AD 2001. Flagellar phase variation of Salmonella enterica serovar Typhimurium contributes to virulence in the murine typhoid infection model but does not influence Salmonella-induced enteropathogenesis. Infect Immun 69: 3021-3030.

Luna MG, Martins MM, Newton SM, Costa SO, Almeida DF, Ferreira LC 1997. Cloning and expression of colonization factor antigen I (CFA/I) epitopes of enterotoxigenic Escherichia coli (ETEC) in Salmonella flagellin. Res Microbiol 148: 217-228.

McClelland M, Sanderson KE, Spieth J, Clifton SW, Latreille P, Courtney L, Porwollik S, Ali J, Dante M, Du F, Hou S, Layman D, Leonard S, Nguyen C, Scott K, Holmes A, Grewal N, Mulvaney E, Ryan E, Sun H, Florea L, Miller W, Stoneking T, Nhan M, Waterston R, Wilson RK 2001. Complete genome sequence of Salmonella enterica serovar Typhimurium LT2. Nature 413: 852-856.

Newton SM, Jacob CO, Stocker BA 1989. Immune response to cholera toxin epitope inserted in Salmonella flagellin. Science 244: 70-72.

Newton SM, Kotb M, Poirier TP, Stocker BA, Beachey EH 1991. Expression and immunogenicity of a streptococcal M protein epitope inserted in Salmonella flagellin. Infect Immun 59: 2158-2165.

Ren T, Zamboni DS, Roy CR, Dietrich WF, Vance RE 2006. Flagellin-deficient Legionella mutants evade caspase-1- and Naip5mediated macrophage immunity. PLoS Pathog 2: e18.

Sanders CJ, Yu Y, Moore DA, Williams IR, Gewirtz AT 2006. Humoral immune response to flagellin requires $\mathrm{T}$ cells and activation of innate immunity. J Immunol 177: 2810-2818.

Sbrogio-Almeida ME, Ferreira LC 2001. Flagellin expressed by live Salmonella vaccine strains induces distinct antibody responses following delivery via systemic or mucosal immunization routes. FEMS Immunol Med Microbiol 30: 203-208.

Sbrogio-Almeida ME, Mosca T, Massis LM, Abrahamsohn IA, Ferreira LC 2004. Host and bacterial factors affecting induction of immune responses to flagellin expressed by attenuated Salmonella vaccine strains. Infect Immun 72: 2546-2555.

Schmieger H 1971. A method for detection of phage mutants with altered transducing ability. Mol Gen Genet 110: 378-381.

Stocker BA 1990. Aromatic-dependent Salmonella as live vaccine presenters of foreign epitopes as inserts in flagellin. Res Microbiol 141: 787-796.

Stocker BA, Newton SM 1994. Immune responses to epitopes inserted in Salmonella flagellin. Int Rev Immunol 11: 167-178.

Yamamoto S, Kutsukake K 2006. FljA-mediated posttranscriptional control of phase 1 flagellin expression in flagellar phase variation of Salmonella enterica serovar Typhimurium. J Bacteriol 188: 958-967. 